Original Research Paper

\title{
Green Synthesis of Silver Nanoparticles using Mediterranean Cypress (Cupressus sempervirens) Leaf Extract
}

\author{
${ }^{1-3}$ Alireza Ebrahiminezhad, ${ }^{1}$ Saeed Taghizadeh and ${ }^{2,3}$ Younes Ghasemi \\ ${ }^{1}$ Department of Medical Biotechnology, \\ School of Medicine and Noncommunicable Diseases Research Centre, Fasa University of Medical Sciences, Fasa, Iran \\ ${ }^{2}$ Department of Medical Nanotechnology, \\ School of Advanced Medical Sciences and Technologies, Shiraz University of Medical Sciences, Shiraz, Iran \\ ${ }^{3}$ Department of Pharmaceutical Biotechnology, \\ School of Pharmacy and Pharmaceutical Sciences Research Centre, Shiraz University of Medical Sciences, Shiraz, Iran
}

Article history

Received: 25-09-2016

Revised: 06-01-2017

Accepted: 01-02-2017

Corresponding Author: Alireza Ebrahiminezhad Department of Medical Biotechnology, School of Medicine and

Noncommunicable Diseases

Research Centre, Fasa

University of Medical Sciences, Fasa, Iran

And

Younes Ghasemi

Department of Pharmaceutical

Biotechnology, School of

Pharmacy and Pharmaceutical

Sciences Research Centre,

Shiraz University of Medical

Sciences, Shiraz, Iran

Email: a ebrahimi@sums.ac.ir; ghasemiy@sums.ac.ir

\begin{abstract}
Silver nanoparticles (AgNPs) retained vast applications in science and technology. Due to the vast application of these particles in various disciplines, there is an interest for synthesis of AgNPs in an environmentally friendly and economic manner. For the first time we were used Mediterranean cypress (Cupressus sempervirens) leaf aqueous extract for biosynthesis of AgNPs. Prepared particles were in various shapes and their diameters were ranging from 10 to $80 \mathrm{~nm}$. TEM micrographs were shown that AgNPs are capped with a biologic matrix. FTIR analysis indicates hydrophilic functional groups in the capping matrix which can improve the stability of AgNPs.
\end{abstract}

Keywords: Ag Nanoparticles, Ag Nanocrystals, Bioreduction, Biosynthesis, Pencil Pine

\section{Introduction}

Nanotechnology is the most growing and widespread scientific and technical achievement of Human beings. This science by applying of nanosize structures emerged as a solution to the previous insoluble problems. Silver nanoparticle (AgNPs) are one of the most studied and applied nanoparticles in medicine and biomedicine. These particles are well known as a potent antimicrobial against almost all bacterial strains (Ebrahiminezhad et al., 2016a; 2016b; 2016d). AgNPs are also effective against antibiotic resistant microorganisms and increase the efficiency of antibiotics (Devi and Joshi, 2012; Fayaz et al., 2011; Ruden et al., 2009; Shahverdi et al., 2007). In addition to antimicrobial applications, AgNPs have various other applications such as molecular labelling and detection, diagnostics, antimicrobial coating, optics, wound healing, antitumor and burn lesson protection and treatment (Sondi and Salopek-Sondi, 2004; Ansari et al., 2011; Alt et al., 2004; Lee et al., 2003; Mukherjee et al., 2008; Mohanpuria et al., 2008; Ebrahimi et al., 2016; Ebrahiminezhad et al., 2016c).

There is increasing consideration on the synthesis and construction of AgNPs and several physical and chemical approaches were developed (Dimitrijevic et al., 2001; Kim et al., 2006; Pal et al., 2009; Pol et al., 2002; Saifuddin et al., 2009; Song et al., 2009; Starowicz et al., 2006). But, there are some major problems with these methods such as high energy consumption, employing extreme and harsh conditions, using organic solvents and chemical agents that can be dangerous to human health and the environment. Green synthesis is the best way to address the problem. Microorganisms and plants are full of bioactive compounds with the capability for reducing and capping AgNPs. By using these compounds AgNPs can be reduced from $\mathrm{Ag}^{+}$ions through bottom up process 
in an eco-friendly manner (Ebrahiminezhad et al., 2016a; 2016b; 2016c; 2016e).

Since now, various microorganisms (i.e., bacteria, fungi and microalgae) were determined for capability to biosynthesise AgNPs (Jain et al., 2010; Parikh et al., 2008; Mandal et al., 2006; Prakash et al., 2010; Sadowski, 2009; Mohammed Fayaz et al., 2011; Kalimuthu et al., 2008; Faghri Zonooz and Salouti, 2011; Bhainsa and D'Souza, 2006; Ingle et al., 2008; 2009; Karbasian et al., 2008). Bioactive compounds from plants are the other source for natural reducing and capping agents. Bioactive compounds from various herbs and plants such as Piper longum, Crataegus douglasii, Nephelium lappaceum, Lippia citriodora, Plukenetia volubilis, Chrysanthemum morifolium, Medicago sativa, Sterculia foetida, Cinnamon zeylanicum, Alcea rosea, Zataria multiflora, Matricaria chamomilla and black tea were used for synthesis of AgNPs in a sustainable manner (Cruz et al., 2010; Vivekanandhan et al., 2014; Reddy et al., 2014; Ghaffari-Moghaddam and Hadi-Dabanlou, 2014; Kumar et al., 2015; 2014; He et al., 2013; Lukman et al., 2011; Rajasekharreddy and Rani, 2014; Sathishkumar et al., 2009; Ebrahiminezhad et al., 2016b; 2016e; 2016c).

Mediterranean cypress (Cupressus sempervirens) is an evergreen tree with a conic crown (Fig. 1). It can grow up to 30 meter but it is about five to seven meter in average. It is also known as Italian cypress, graveyard cypress, Tuscan cypress and pencil pine. This tree is habituated in a vast geographical region in the eastern Mediterranean including Cyprus, northern Egypt, western Syria, Lebanon and Iran. Also it could be found in Europe continent such as southern Greece, Albania, Croatia and Italy. Mediterranean cypress is the most dominant tree in Iranian Gardens and plays a central role in their design. Mediterranean cypress is an aromatic plant and it's leafy branches have a high volatile oil content (Tapondjou et al., 2005). In this study for the first time we have used the aqueous extract of Mediterranean cypress leafy branches as a sustainable, cheap and available material for synthesis of AgNPs in an environmentally friendly manner.

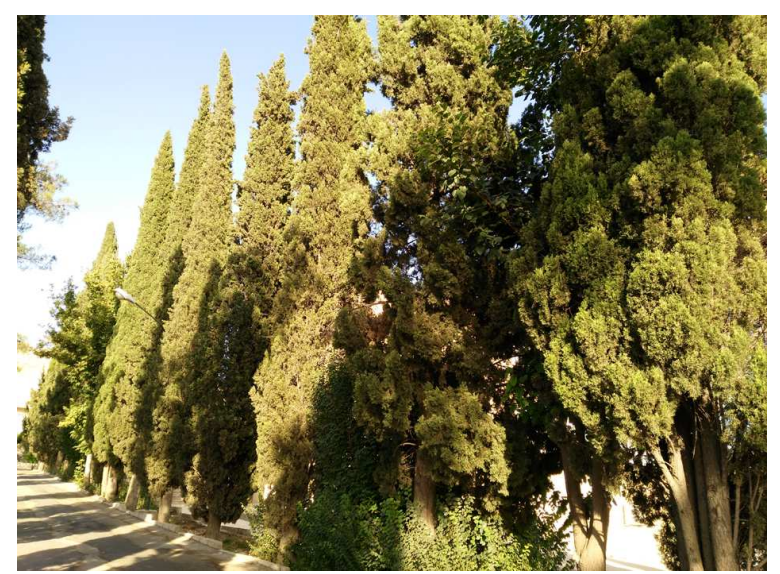

Fig. 1. Mediterranean cypress (C. sempervirens) trees

\section{Materials and Methods}

\section{Chemicals}

$\mathrm{AgNO}_{3}$ was obtained from Merck chemicals (Catalogue Number: 101512). Glass-wares were washed with concentrated hydrochloric acid and deionised water. Milli-Q ultrapure deionized water (resistance $>18 \mathrm{M} \Omega$ $\mathrm{cm}^{-1}$ ) was used for the all purposes.

\section{Leaf Extract Preparation}

Leaf branches of Mediterranean cypress (C. sempervirens) were harvested and washed with deionised water $\left(\mathrm{diH}_{2} \mathrm{O}\right)$ to remove the potential dost and mods and were dried in room condition (Fig. 2). To prepare leaf extract, $5 \mathrm{~g}$ of dried leaves were measured and heated in $100 \mathrm{~mL} \mathrm{diH}{ }_{2} \mathrm{O}$. After boiling for $10 \mathrm{~min}$ the mixture was filtered to remove the leaf particles. Filtrate was centrifuged for $15 \mathrm{~min}$ at $5000 \mathrm{rpm}$ to remove the remaining particles. The obtained clear supernatant was refrigerated and used for synthesis reaction.

\section{Synthesis of Silver Nanoparticles}

One $\mathrm{mL}$ silver nitrate $(50 \mathrm{mM})$ was added to $9 \mathrm{~mL}$ leaf extract under vigorous stirring. In our previous investigations we found that $5 \mathrm{mM}$ silver nitrate is the best concentration for green synthesis of AgNPs (Ebrahiminezhad et al., 2016e; 2016b). So, in this experiment final concentration of silver nitrate was set to be $5 \mathrm{mM}$. The reaction was followed for $12 \mathrm{~h}$ at room temperature.

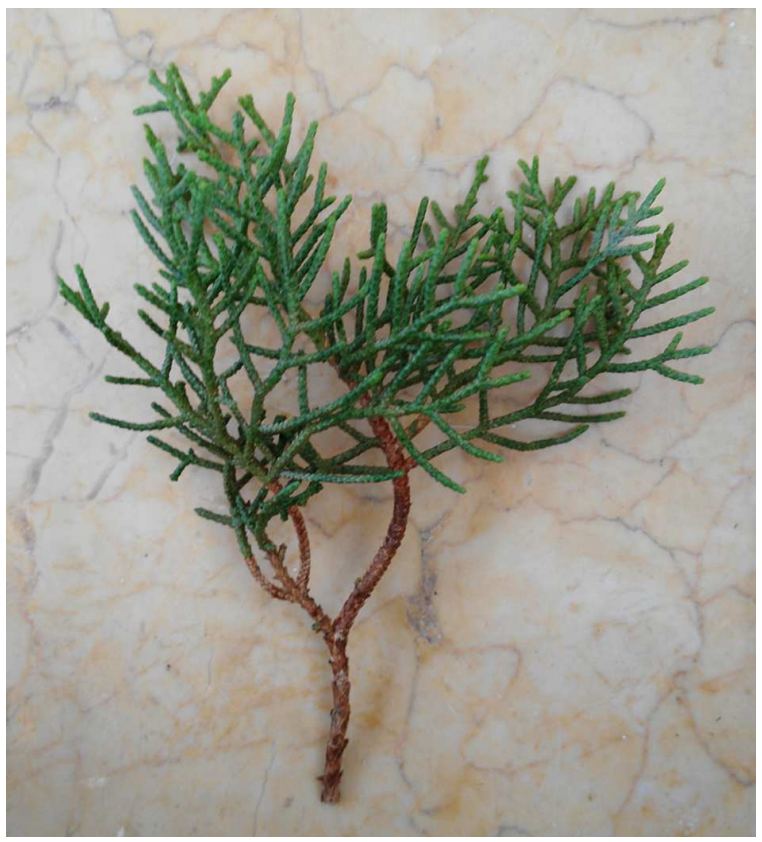

Fig. 2. Dried leaf branch of Mediterranean cypress (C. sempervirens) 


\section{Characterization of Silver Nanoparticles}

The UV-vis absorption spectra of synthesised nanoparticles were recorded from 300 to $700 \mathrm{~nm}$ by T80+ $\mathrm{UV} / \mathrm{Vis}$ Spectrometer PG Instruments Ltd. Size and morphology of prepared nanoparticles were evaluated by Transmission Electron Microscopy (TEM, Philips, CM 10; HT $100 \mathrm{Kv}$ ). X-ray powder diffraction (XRD, Siemens D5000) analysis was done to determine the crystallinity of prepared AgNPs. Functional groups of the phytochemicals which coat the prepared nanoparticles were determined by Fourier transformed infrared spectroscopy (Bruker, Vertex 70, FTIR Spectrometer) (Ebrahiminezhad et al., 2013; Gholami et al., 2015).

\section{Results and Discussion}

By adding silver nitrate solution to the leaf extract a change in the reaction colour was occurred after a few seconds which is an indicative for the formation of AgNPs. After $12 \mathrm{~h}$ stirring the reaction colour was changed from green to dark brown. There is a typical UV-vis absorption peak of AgNPs at $453 \mathrm{~nm}$ (Fig. 3). This absorption peak is the characteristic feature of AgNPs which is due to Surface Plasmon Resonance (SPR) (Ebrahimi et al., 2016; Ebrahiminezhad et al., 2016a; 2016b; 2016c; 2016e).

Prepared colloidal suspension of AgNPs was visualized with TEM analysis (Fig. 4). Prepared AgNPs were ranging from 10 to $80 \mathrm{~nm}$ in diameter with various shapes such as spherical, hexahedral, oval and truncated triangle. The particles were surrounded by a matrix from C. sempervirens leaf extract. This matrix is usually composed of large biomolecules with hydrophilic functional groups, as shown by FTIR analysis in following, which can stabilise AgNPs and make the particles colloidally stable in aqueous matrixes (Ebrahiminezhad et al., 2016a; 2016b; 2016c; 2016e).

The crystal structure of prepared particles was evaluated using XRD analysis (Fig. 5b) (Ebrahiminezhad et al., 2016f; 2015b). The main diffraction peaks appeared at 38 and $44^{\circ}$ of 2è degrees (Ebrahiminezhad et al., 2016b; 2016c; 2016e). The peaks were identified using peak search tool on the PANalytical X'Pert HighScore software while parameters were set as minimum significance $(0.75)$, minimum tip width $\left(0.00^{\circ}\right.$ of $2 \theta$ values), maximum tip width $\left(1.00^{\circ}\right.$ of $2 \theta$ values $)$ and peak base width $\left(2.00^{\circ}\right.$ of $2 \theta$ values). In addition to characteristic silver peaks, there are other peaks which indicated by asterisk. Similar peaks also reported elsewhere and discussed as mineral complexes such as $\mathrm{Ag}_{3} \mathrm{PO}_{4}$ (Ebrahiminezhad et al., 2016a).

FTIR spectra of the prepared AgNPs can be found in Fig. 6. The characteristic peak of $\mathrm{C}-\mathrm{O}$ bond was observed at $1015 \mathrm{~cm}^{-1}$ (Ebrahiminezhad et al., 2014a).

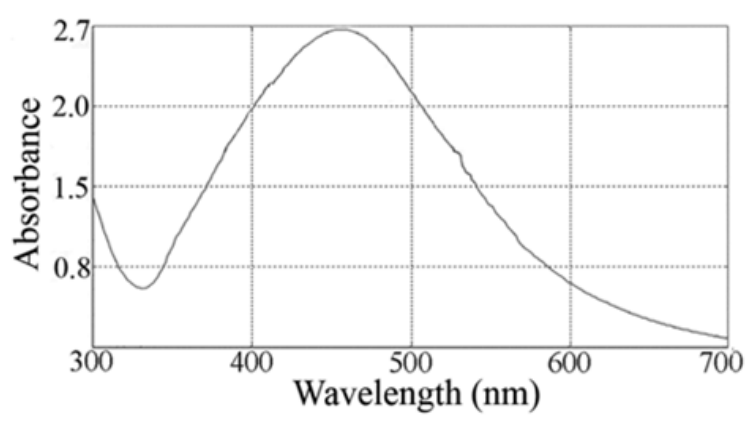

Fig. 3. UV-vis spectra of the prepared AgNPs with the absorption peak at $453 \mathrm{~nm}$

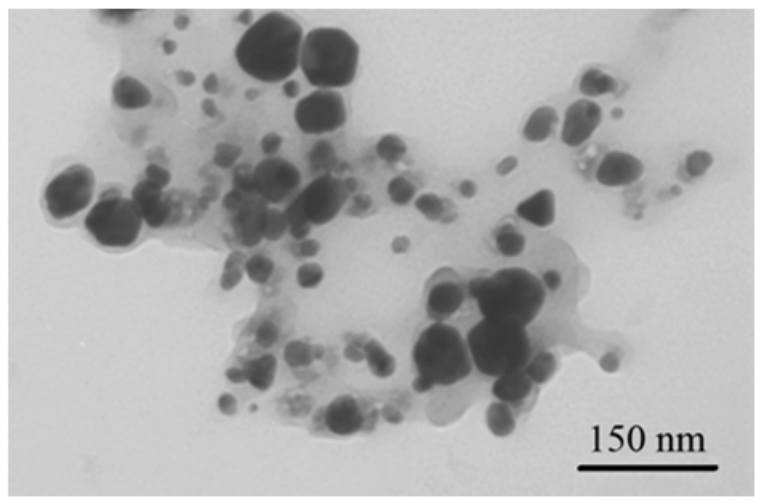

Fig. 4. TEM micrograph of the prepared AgNPs with biologic capping

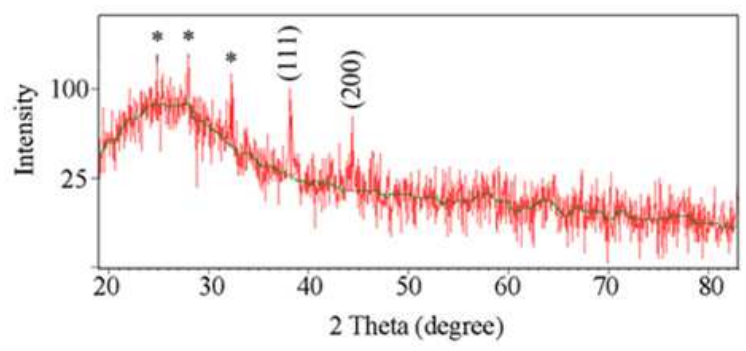

Fig. 5. XRD pattern of green synthesised AgNPs

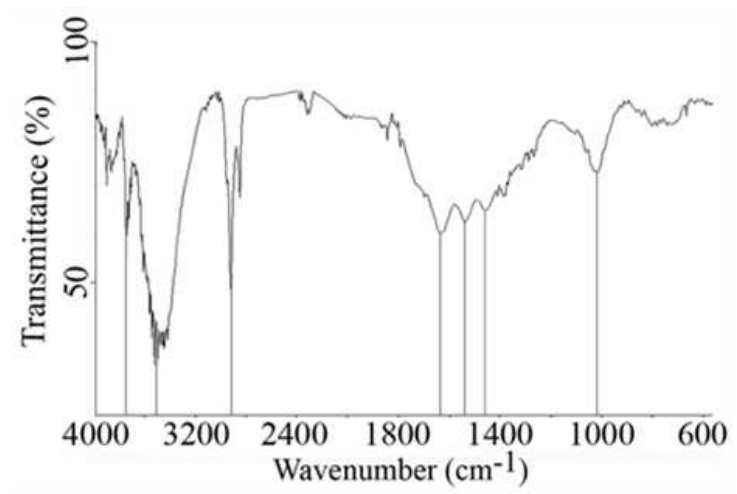

Fig. 6. FTIR spectra of the prepared AgNPs 
Absorption due to carbon-carbon double bond was appeared at $1548 \mathrm{~cm}^{-1}$. Carbonyl groups absorption peak was recorded at $1624 \mathrm{~cm}^{-1}$ (Ebrahiminezhad et al., $2014 \mathrm{~b} ; 2015 \mathrm{a})$. The bond at $1468 \mathrm{~cm}^{-1}$ was from $\mathrm{C}-\mathrm{H}$ bending vibrations and its corresponding stretching vibration peaks was appeared at about $2900 \mathrm{~cm}^{-1}$ (Ebrahiminezhad et al., 2012a). Hydrogen bonds produced a broad peak at $3524 \mathrm{~cm}^{-1}$ and free $\mathrm{OH}$ groups formed a sharp peak at $3750 \mathrm{~cm}^{-1}$. These findings are in concomitance with previous reports which introduce the oxygen bearing functional groups as the main anchor groups for entrapment and reduction of metal ions and subsequently interactions of organic compounds with nanoparticles surface (Ebrahiminezhad et al., 2016a; 2016b; 2016c; 2012b; 2016e).

\section{Conclusion}

Plants are abundant sources for natural and sustainable compounds which are useful for green synthesis of nanostructures and particularly AgNPs. In this regard, for the first time we have been used Mediterranean cypress (C. sempervirens) aqueous leaf extract for green synthesis of AgNPs in a bottom up manner using silver nitrate as silver precursor. C. sempervirens leaf extract contains bioactive compounds which can act as reducing and capping agent for biosynthesis of AgNPs. Prepared particles were surrounded with natural compounds from C. sempervirens. This matrix has hydrophilic functional groups that can make the particles colloidally stable in aqueous environment. The $\mathrm{Ag}+$ ions reduction was conducted at room temperature without applying any harsh reaction condition. This synthesis condition is so interesting from the economical point of view for production of AgNPs in industrial scales.

\section{Acknowledgement}

This work was financially supported by Fasa University of Medical Sciences.

\section{Author's Contributions}

Alireza Ebrahiminezhad: Designed the research plan, participated in all experiments, coordinated the data-analysis and writing the manuscript.

Saeed Taghizadeh: Contribute in the experimental works.

Younes Ghasemi: Head of the Pharmaceutical Sciences Research Centre, coordinated and organized the study.

\section{Ethics}

The authors declare that they have no competing interests in this work.

\section{References}

Alt, V., T. Bechert, P. Steinrücke, M. Wagener and P. Seidel et al., 2004. An in vitro assessment of the antibacterial properties and cytotoxicity of nanoparticulate silver bone cement. Biomaterials, 25: 4383-4391.

DOI: $10.1016 /$ j.biomaterials.2003.10.078

Ansari, M., H. Khan, A. Khan, A. Malik and A. Sultan et al., 2011. Evaluation of antibacterial activity of silver nanoparticles against MSSA and MRSA on isolates from skin infections. Biol. Med., 3: 141-146.

Bhainsa, K.C. and S. D'souza, 2006. Extracellular biosynthesis of silver nanoparticles using the fungus Aspergillus fumigatus. Colloids Surf. B., 47: 160-164. DOI: 10.1016/j.colsurfb.2005.11.026

Cruz, D., P.L. Falé, A. Mourato, P.D. Vaz and M. Luisa Serralheiro et al., 2010. Preparation and physicochemical characterization of $\mathrm{Ag}$ nanoparticles biosynthesized by Lippia citriodora (Lemon Verbena). Colloids Surf. B., 81: 67-73. DOI: 10.1016/j.colsurfb.2010.06.025

Devi, L.S. and S. Joshi, 2012. Antimicrobial and synergistic effects of silver nanoparticles synthesized using soil fungi of high altitudes of Eastern Himalaya. Mycobiology, 40: 27-34. DOI: $10.5941 / \mathrm{MYCO} .2012 .40 .1 .027$

Dimitrijevic, N.M., D.M. Bartels, C.D. Jonah, K. Takahashi and T. Rajh, 2001. Radiolytically induced formation and optical absorption spectra of colloidal silver nanoparticles in supercritical ethane. J. Phys. Chem. B, 105: 954-959. DOI: 10.1021/jp0028296

Ebrahimi, N., S. Rasoul-Amini, A. Ebrahiminezhad, Y. Ghasemi and A. Gholami et al., 2016. Comparative study on characteristics and cytotoxicity of bifunctional magnetic-silver nanostructures: Synthesized using three different reducing agents. Acta Metallurgica Sinica (English Letters), 29: 326-334. DOI: 10.1007/s40195-016-0399-9

Ebrahiminezhad, A., M. Bagheri, S. Taghizadeh, A. Berenjian and Y. Ghasemi, 2016a. Biomimetic synthesis of silver nanoparticles using microalgal secretory carbohydrates as a novel anticancer and antimicrobial agent. Adv. Natural Sci. Nanosci. Nanotechnol. DOI: 10.1088/2043-6262/7/1/015018

Ebrahiminezhad, A., Y. Barzegar, Y. Ghasemi and A. Berenjian, 2016b. Green synthesis and characterization of silver nanoparticles using Alcea rosea flower extract as a new generation of antimicrobials. Chem. Ind. Chem. Eng. Q. DOI: 10.2298/CICEQ150824002E

Ebrahiminezhad, A., A. Berenjian and Y. Ghasemi, 2016c. Template free synthesis of natural carbohydrates functionalised fluorescent silver nanoclusters. IET Nanobiotechnology, 10: 120-124. DOI: 10.1049 /iet-nbt.2015.0072

Ebrahiminezhad, A., M.J. Raee, Z. Manafi, A.S. Jahromi and Y. Ghasemi, 2016d. Ancient and novel forms of silver in medicine and biomedicine. J. Adv. Med. Sci. Applied Technol., 2: 122-128. 
Ebrahiminezhad, A., S. Taghizadeh, A. Berenjiand, A. Rahi and Y. Ghasemi, 2016e. Synthesis and characterization of silver nanoparticles with natural carbohydrate capping using Zataria multiflora. Adv. Mater. Lett., 7: 122-127. DOI: $10.5185 /$ amlett.2016.6458

Ebrahiminezhad, A., V. Varma, S. Yang and A. Berenjian, 2016f. Magnetic immobilization of Bacillus subtilis natto cells for menaquinone-7 fermentation. Applied Microbiol. Biotechnol., 100: 173-180. DOI: $10.1007 / \mathrm{s} 00253-015-6977-3$

Ebrahiminezhad, A., S. Rasoul-Amini, A. Kouhpayeh, S. Davaran and J. Barar et al., 2015a. Impacts of amine functionalized iron oxide nanoparticles on HepG2 cell line. Curr Nanosci., 11: 113-119.

DOI: $10.2174 / 1573413710666140911224743$

Ebrahiminezhad, A., V. Varma, S. Yang, Y. Ghasemi and A. Berenjian, 2015b. Synthesis and application of amine functionalized iron oxide nanoparticles on menaquinone-7 fermentation: A step towards process intensification. Nanomaterials, 6: 1-9. DOI: 10.3390/nano6010001

Ebrahiminezhad, A., S. Davaran, S. Rasoul-Amini, J. Barar and M. Moghadam et al., 2012a. Synthesis, characterization and anti-Listeria monocytogenes effect of amino acid coated magnetite nanoparticles. Curr. Nanosci., 8: 868-874.

DOI: $10.2174 / 157341312803989178$

Ebrahiminezhad, A., Y. Ghasemi, S. Rasoul-Amini, J. Barar and S. Davaran, 2012b. Impact of amino-acid coating on the synthesis and characteristics of IronOxide Nanoparticles (IONs). Bull. Korean Chem. Soc., 33: 3957-3962.

DOI: $10.5012 /$ bkcs.2012.33.12.3957

Ebrahiminezhad, A., Y. Ghasemi, S. Rasoul-Amini, J. Barar and S. Davaran, 2013. Preparation of novel magnetic fluorescent nanoparticles using amino acids. Colloids Surf. B., 102: 534-539.

DOI: 10.1016/j.colsurfb.2012.08.046

Ebrahiminezhad, A., S. Najafipour, A. Kouhpayeh, A. Berenjian and S. Rasoul-Amini et al., 2014a. Facile fabrication of uniform hollow silica microspheres using a novel biological template. Colloids Surf. B., 118: 249-253. DOI: 10.1016/j.colsurfb.2014.03.052

Ebrahiminezhad, A., S. Rasoul-Amini, S. Davaran, J. Barar and Y. Ghasemi, 2014b. Impacts of iron oxide nanoparticles on the invasion power of Listeria monocytogenes. Curr Nanosci., 10: 382-388. DOI: $10.2174 / 15734137113096660109$

Faghri Zonooz, N. and M. Salouti, 2011. Extracellular biosynthesis of silver nanoparticles using cell filtrate of Streptomyces sp. ERI-3. Sci. Iranica, 18: 1631-1635. DOI: 10.1016/j.scient.2011.11.029

Fayaz, A.M., K. Balaji, M. Girilal, R. Yadav and P.T. Kalaichelvan et al., 2010. Biogenic synthesis of silver nanoparticles and their synergistic effect with antibiotics: A study against gram-positive and gramnegative bacteria. Nanomed. Nanotechnol. Biol. Med., 6: 103-109. DOI: 10.1016/j.nano.2009.04.006
Ghaffari-Moghaddam, M. and R. Hadi-Dabanlou, 2014. Plant mediated green synthesis and antibacterial activity of silver nanoparticles using Crataegus douglasii fruit extract. J. Ind. Eng. Chem., 20: 739-744. DOI: $10.1016 /$ j.jiec.2013.09.005

Gholami, A., S. Rasoul-Amini, A. Ebrahiminezhad, S.H. Seradj and Y. Ghasemi, 2015. Lipoamino acid coated superparamagnetic iron oxide nanoparticles concentration and time dependently enhanced growth of human hepatocarcinoma cell line (HepG2). J. Nanomaterials. DOI: 10.1155/2015/451405

He, Y., Z. Du, H. Lv, Q. Jia and Z. Tang et al., 2013. Green synthesis of silver nanoparticles by Chrysanthemum morifolium Ramat. extract and their application in clinical ultrasound gel. Int. J. Nanomed., 8: 1809-1815. DOI: 10.2147/IJN.S43289

Ingle, A., A. Gade, S. Pierrat, C. Sonnichsen and M. Rai, 2008. Mycosynthesis of silver nanoparticles using the fungus Fusarium acuminatum and its activity against some human pathogenic bacteria. Curr Nanosci., 4: 141-144. DOI: 10.2174/157341308784340804

Ingle, A., M. Rai, A. Gade and M. Bawaskar, 2009. Fusarium solani: A novel biological agent for the extracellular synthesis of silver nanoparticles. J. Nanopart. Res., 11: 2079-2085. DOI: $10.1007 / \mathrm{s} 11051-008-9573-y$

Jain, D., S. Kachhwaha, R. Jain, G. Srivastava and S. Kothari, 2010. Novel microbial route to synthesize silver nanoparticles using spore crystal mixture of Bacillus thuringiensis. Indian J. Exp. Biol., 48: 1152-1156. PMID: 21117457

Kalimuthu, K., R. Suresh Babu, D. Venkataraman, M. Bilal and S. Gurunathan, 2008. Biosynthesis of silver nanocrystals by Bacillus licheniformis. Colloids Surf. B., 65: 150-153.

DOI: $10.1016 /$ j.colsurfb.2008.02.018

Karbasian, M., S. Atyabi, S. Siadat, S. Momen and D. Norouzian, 2008. Optimizing nano-silver formation by Fusarium oxysporum PTCC 5115 employing response surface methodology. Am. J. Agric. Biol. Sci., 3: 433-437. DOI: 10.3844/ajabssp.2008.433.437

Kim, H.S., K.H. Lee and S.G. Kim, 2006. Growth of monodisperse silver nanoparticles in polymer matrix by spray pyrolysis. Aerosol Sci. Technol., 40: 536-544. DOI: 10.1080/02786820600714361

Kumar, B., K. Smita, L. Cumbal and Y. Angulo, 2015. Fabrication of silver nanoplates using Nephelium lappaceum (Rambutan) peel: A sustainable approach. J. Mol. Liq., 211: 476-480. DOI: 10.1016/j.molliq.2015.07.067

Kumar, B., K. Smita, L. Cumbal and A. Debut, 2014. Synthesis of silver nanoparticles using Sacha inchi (Plukenetia volubilis L.) leaf extracts. Saudi J. Biol. Sci., 21: 605-609. DOI: 10.1016/j.sjbs.2014.07.004

Lee, H., S. Yeo and S. Jeong, 2003. Antibacterial effect of nanosized silver colloidal solution on textile fabrics. J. Mater. Sci., 38: 2199-2204.

DOI: $10.1023 / \mathrm{A}: 1023736416361$ 
Lukman, A.I., B. Gong, C.E. Marjo, U. Roessner and A.T. Harris, 2011. Facile synthesis, stabilization and anti-bacterial performance of discrete $\mathrm{Ag}$ nanoparticles using Medicago sativa seed exudates. J. Colloid Interface Sci., 353: 433-444.

DOI: $10.1016 /$ j.jcis.2010.09.088

Mandal, D., M.E. Bolander, D. Mukhopadhyay, G. Sarkar and P. Mukherjee, 2006. The use of microorganisms for the formation of metal nanoparticles and their application. Applied Microbiol. Biotechnol., 69: 485-492. DOI: 10.1007/s00253-005-0179-3

Mohammed Fayaz, A., M. Girilal, M. Rahman, R. Venkatesan and P. Kalaichelvan, 2011. Biosynthesis of silver and gold nanoparticles using thermophilic bacterium Geobacillus stearothermophilus. Process Biochem., 46: 1958-1962. DOI: 10.1016/j.procbio.2011.07.003

Mohanpuria, P., N.K. Rana and S.K. Yadav, 2008. Biosynthesis of nanoparticles: Technological concepts and future applications. J. Nanopart. Res., 10: 507-517. DOI: 10.1007/s11051-007-9275-X

Mukherjee, P., M. Roy, B. Mandal, G. Dey and P. Mukherjee et al., 2008. Green synthesis of highly stabilized nanocrystalline silver particles by a nonpathogenic and agriculturally important fungus $T$. asperellum. Nanotechnol., 19: 075103-075103. PMID: 21817628

Pal, A., S. Shah and S. Devi, 2009. Microwave-assisted synthesis of silver nanoparticles using ethanol as a reducing agent. Mater. Chem. Phys., 114: 530-532. DOI: 10.1016/j.matchemphys.2008.11.056

Parikh, R.Y., S. Singh, B. Prasad, M.S. Patole and M. Sastry et al., 2008. Extracellular synthesis of crystalline silver nanoparticles and molecular evidence of silver resistance from Morganella sp.: Towards understanding biochemical synthesis mechanism. ChemBioChem, 9: 1415-1422. DOI: $10.1002 /$ cbic. 200700592

Pol, V.G., D. Srivastava, O. Palchik, V. Palchik and M. Slifkin et al., 2002. Sonochemical deposition of silver nanoparticles on silica spheres. Langmuir, 18: 3352-3357. DOI: 10.1021/la0155552

Prakash, A., S. Sharma, N. Ahmad, A. Ghosh and P. Sinha, 2010. Bacteria mediated extracellular synthesis of metallic nanoparticles. Int. Res. J. Biotechnol., 1: 71-79.

Rajasekharreddy, P. and P.U. Rani, 2014. Biofabrication of Ag nanoparticles using Sterculia foetida L. seed extract and their toxic potential against mosquito vectors and HeLa cancer cells. Mater. Sci. Eng., C, 39: 203-212. DOI: 10.1016/j.msec.2014.03.003

Reddy, N.J., D. Nagoor Vali, M. Rani and S.S. Rani, 2014. Evaluation of antioxidant, antibacterial and cytotoxic effects of green synthesized silver nanoparticles by Piper longum fruit. Mater. Sci. Eng., C, 34: 115-122.

DOI: $10.1016 /$ j.msec.2013.08.039
Ruden, S., K. Hilpert, M. Berditsch, P. Wadhwani and A.S. Ulrich, 2009. Synergistic interaction between silver nanoparticles and membrane-permeabilizing antimicrobial peptides. Antimicrob. Agents Chemother., 53: 3538-3540.

DOI: 10.1128/AAC.01106-08

Sadowski, Z., 2009. Biosynthesis and Application of Silver and Gold Nanoparticles. In: Silver Nanoparticles, Perez, D.P. (Ed.), Rijeka, InTech.

Saifuddin, N., C. Wong and A. Yasumira, 2009. Rapid biosynthesis of silver nanoparticles using culture supernatant of bacteria with microwave irradiation. J. Chem., 6: 61-70. DOI: 10.1155/2009/734264

Sathishkumar, M., K. Sneha, S. Won, C.W. Cho and S. Kim et al., 2009. Cinnamon zeylanicum bark extract and powder mediated green synthesis of nano-crystalline silver particles and its bactericidal activity. Colloids Surf. B., 73: 332-338.

DOI: 10.1016/j.colsurfb.2009.06.005

Shahverdi, A.R., A. Fakhimi, H.R. Shahverdi and S. Minaian, 2007. Synthesis and effect of silver nanoparticles on the antibacterial activity of different antibiotics against Staphylococcus aureus and Escherichia coli. Nanomed. Nanotechnol. Biol. Med., 3: 168-171. DOI: 10.1016/j.nano.2007.02.001

Sondi, I. and B. Salopek-Sondi, 2004. Silver nanoparticles as antimicrobial agent: A case study on E. coli as a model for Gram-negative bacteria. J. Colloid Interface Sci., 275: 177-182. DOI: 10.1016/j.jcis.2004.02.012

Song, K.C., S.M. Lee, T.S. Park and B.S. Lee, 2009. Preparation of colloidal silver nanoparticles by chemical reduction method. Korean J. Chem. Eng., 26: 153-155. DOI: 10.1007/s1 1814-009-0024-y

Starowicz, M., B. Stypuła and J. Banaś, 2006. Electrochemical synthesis of silver nanoparticles. Electrochem. Commun., 8: 227-230. DOI: $10.1016 /$ j.elecom.2005.11.018

Tapondjou, A.L., C. Adler, D.A. Fontem, H. Bouda and C. Reichmuth, 2005. Bioactivities of cymol and essential oils of Cupressus sempervirens and Eucalyptus saligna against Sitophilus zeamais Motschulsky and Tribolium confusum du Val. J. Stored Prod. Res., 41: 91-102. DOI: 10.1016/j.jspr.2004.01.004

Vivekanandhan, S., M. Schreiber, C. Mason, A.K. Mohanty and M. Misra, 2014. Maple leaf (Acer sp.) extract mediated green process for the functionalization of $\mathrm{ZnO}$ powders with silver nanoparticles. Colloids Surf. B., 113: 169-175. DOI: 10.1016/j.colsurfb.2013.08.033 